\title{
Bite Angle Effects of Diphosphines in Carbonylation Reactions
}

Piet W.N.M. van Leeuwen, Zoraida Freixa

\section{1}

\section{Introduction}

The first two wide bite angle diphosphines, BISBI [1] and Xantphos [2], were introduced with the aim of improving the selectivity for linear aldehyde in the rhodium-catalyzed hydroformylation reaction. For designing Xantphos and related ligands, molecular mechanics methods were used. The concept of the natural bite angle $\beta_{\mathrm{n}}$, that is, the ligand backbone preferred bite angle, was introduced by Casey and Whiteker [3], and $\beta_{\mathrm{n}}$ can be easily obtained by using molecular mechanics calculations. This angle gives the relative magnitudes of bite angles of the bidentate ligands, but it does not predict the angles for X-ray structures for two reasons. First, because the parameter for phosphorus-metal-phosphorus bending, the metal preferred bite angle, is set to zero in these calculations. Second, while parameters for the organic part of the molecules are highly accurate, the parameters involving the metal (for bond stretch and dihedral bending) are inaccurate and variable, but this need not distort the relative order of the ligands. The effect on hydroformylation was fairly well predicted and so was the favorable effect on metal-catalyzed hydrocyanation [4]. The bite angle effect on the activity or selectivity has been studied and reviewed for many catalytic reactions [5-9]. Initially for palladium-catalyzed reactions the results seemed rather capricious, but today these reactions are understood reasonably well [10].

For our study of the effect of (wide) bite angle diphosphines on catalytic reactions, a distinction between two different effects, both related to the bite angle of diphosphine ligands, can be made [5]:

- The first one, which we have called the steric bite angle effect, is related to the steric interactions (ligand-ligand or ligand-substrate) generated when the bite angle is modified by changing the backbone and keeping the substituents at the phosphorus donor atom the same. The resulting steric interactions can change the energies of the transition and the catalyst resting states. In rhodium-catalyzed hydroformylation reactions steric effects dominate [11], although an electronic bite angle effect was observed in one instance [12]. 
- The second one, the electronic bite angle effect, is associated with electronic changes in the catalytic center when changing the bite angle [9]. It can be described as an orbital effect, because the bite angle determines metal hybridization and as a consequence metal orbital energies and reactivity. This effect can also manifest itself as a stabilization or destabilization of the initial, final, or transition state of a reaction. The reductive elimination occurring in hydrocyanation and cross-coupling catalysis is an example of an electronic bite angle effect.

\section{2}

\section{Rhodium-Catalyzed Hydroformylation}

\subsection{1}

\section{Introduction}

The hydroformylation of alkenes is one of the most extensively applied homogeneous catalytic processes in industry. More than 9 million tons of aldehydes and alcohols are produced annually [13]. Many efforts have been devoted in the last few years to the development of systems with improved regioselectivity toward the formation of the industrially more important linear aldehyde. Both phosphine- and phosphite-based systems giving high regioselectivities to linear aldehyde for the hydroformylation of terminal and internal alkenes have been reported [1,2,14-16] (Scheme 1.1).

The generally accepted mechanism for the rhodium triphenylphosphine catalyzed hydroformylation reaction as proposed by Heck and Breslow [17] is shown in Scheme 1.2. The catalytically active species is a trigonal bipyramidal hydrido rhodium complex, which usually contains two phosphorus donor ligands. In early mechanistic studies [18], it was already demonstrated that this catalyst exists with two isomeric structures, depending on the coordination of the triphenylphosphine ligands, namely, equatorial-equatorial (ee) and equatorial-apical (ea) in an 85/15 ratio. Ever since the first rhodium-phosphine system was developed, a lot of research has been devoted to the development of more active and selective systems. In 1987, Devon et al. at Texas Eastman [1] patented the BISBI-rhodium catalyst, which gave excellent selectivity toward the linear aldehyde compared to other diphosphine ligands previously studied [19]. To rationalize this result, Casey and Whiteker [15] studied the relationship between selectivity and bite angle for different diphosphine ligands. They found a good correlation between the bite angle of the diphosphines and the

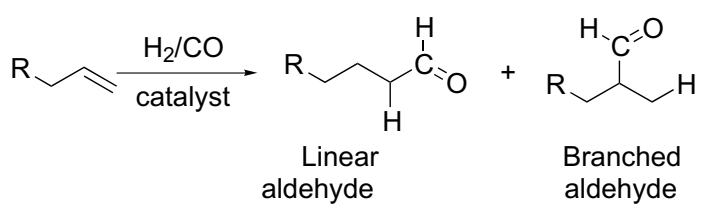

Scheme 1.1 The hydroformylation reaction. 
<smiles>Pc1cccc2c1Oc1c(P)cccc1CC2</smiles>

1, Homoxantphos<smiles>C[Si]1(C)c2cccc(P)c2Oc2c(P)cccc21</smiles>

3, Sixantphos<smiles>CC1(C)c2cccc(P)c2Oc2c(P)cccc21</smiles>

5, Xantphos<smiles>[R]Nc1cccc(P)c1Oc1c(P)cccc1P</smiles>

7, R = Bn, Benzylnixantphos

8, $\mathrm{R}=\mathrm{H}$, Nixantphos<smiles>Pc1cccc(Oc2c(P)cccc2P(c2ccccc2)c2ccccc2)c1P</smiles>

2, Phosxantphos<smiles>[R20]c1cc(C)cc2c1Oc1c(P)cc(C)cc1S2</smiles>

4d, R = Ph, Thixantphos<smiles>CC(C)=C1c2cccc(P)c2Oc2c(P)cccc21</smiles>

6, Isopropxantphos<smiles>Pc1ccc2cccc3c2c1Oc1ccccc1-3</smiles>

9, Benzoxantphos

regioselectivity. The high regioselectivity observed with BISBI was attributed to the preferential coordination mode, ee, in the catalytically active $[\mathrm{RhH}$ (diphosphine) $(\mathrm{CO})_{2}$ ] species, due to BISBI's natural bite angle close to $120^{\circ}$.

In the last decade, van Leeuwen et al. synthesized a series of xantphos-type diphosphines possessing backbones related to xanthene and having natural bite angles ranging from $102^{\circ}$ to $123^{\circ}$ [2]. These ligands, designed to ensure the bite angle is the only factor that has a significant variation within the series (the differences in electronic properties are minimal), have been applied to study the bite angle effect on the coordination mode, selectivity, and activity in hydroformylation (Scheme 1.2).

\subsection{2}

\section{Steric Bite Angle Effect and Regioselectivity}

In the first publication on the xantphos series [2], a regular increase in the selectivity to linear product in 1-octene hydroformylation while increasing the bite angle was 


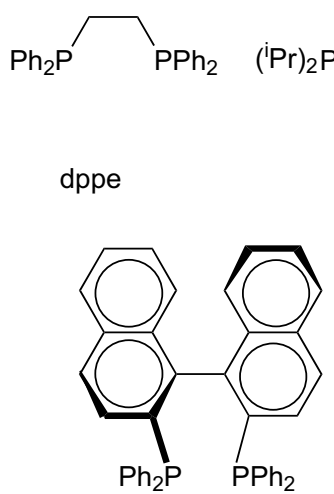

(S)-BINAP

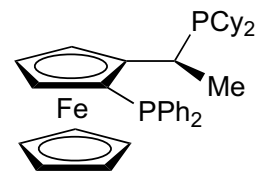

(R)-(S)-Josiphos<smiles>CC1(C)O[C@@H](Cc2ccccc2)[C@@H](Cc2ccccc2)O1</smiles>

dippe $\quad(R, R)$-DIOP

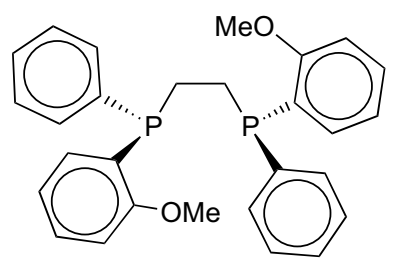

$(R, R)$-DIPAMP

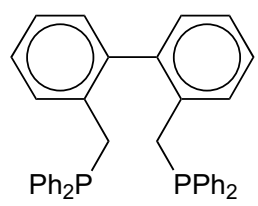

BISBI

reported. The suggestion of a shift in the ee : ea equilibrium in the rhodium hydride resting state toward the ee isomer, considered to be the more selective one, was the tentative explanation. Later studies $[16,20,21]$ (Table 1.1) showed that, even though there is a clear bite angle-selectivity correlation when a wide range of angles

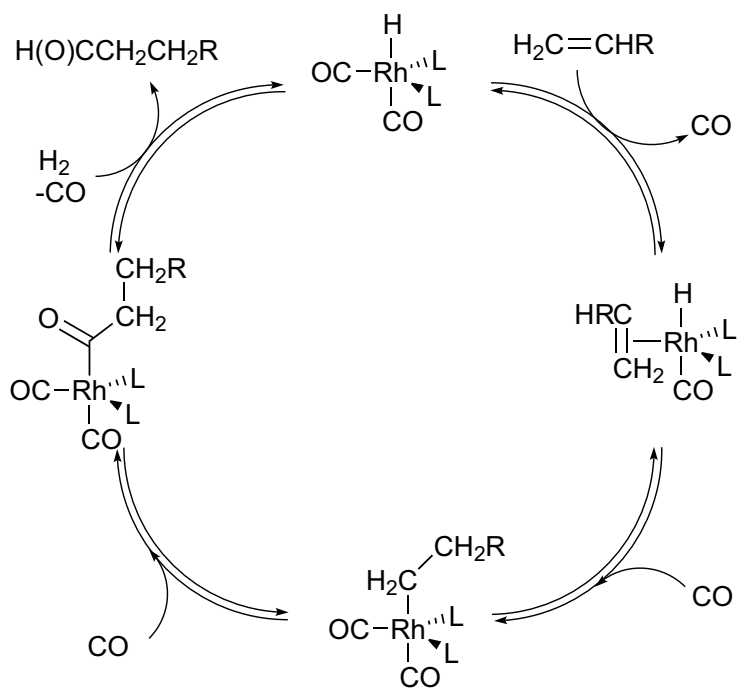

Scheme 1.2 Simplified catalytic cycle for the hydroformylation reaction. 
Table 1.1 1-Octene hydroformylation using xantphos ligands (1-10). ${ }^{a}$

\begin{tabular}{llllllc}
\hline Ligand & $\boldsymbol{\beta}_{\mathbf{n}}\left(^{\left.{ }^{\circ}\right)^{\boldsymbol{b}}}\right.$ & I/b ratio $^{\boldsymbol{c}}$ & \% linear aldehyde & \% isomer & tof $^{c, \boldsymbol{d}}$ & ee: ea ratio \\
\hline $\mathbf{1}$ & 102.0 & 8.5 & 88.2 & 1.4 & 37 & $3: 7$ \\
$\mathbf{2}$ & 107.9 & 14.6 & 89.7 & 4.2 & 74 & $7: 3$ \\
$\mathbf{3}$ & 108.5 & 34.6 & 94.3 & 3.0 & 81 & $6: 4$ \\
$\mathbf{4 d}$ & 109.6 & 50.0 & 93.2 & 4.9 & 110 & $7: 3$ \\
$\mathbf{5}$ & 111.4 & 52.2 & 94.5 & 3.6 & 187 & $7: 3$ \\
$\mathbf{6}$ & 113.2 & 49.8 & 94.3 & 3.8 & 162 & $8: 2$ \\
$\mathbf{7}$ & 114.1 & 50.6 & 94.3 & 3.9 & 154 & $7: 3$ \\
$\mathbf{8}$ & 114.2 & 69.4 & 94.9 & 3.7 & 160 & $8: 2$ \\
$\mathbf{9}$ & 120.6 & 50.2 & 96.5 & 1.6 & 343 & $6: 4$ \\
$\mathbf{1 0}$ & 123.1 & 66.9 & 88.7 & 10.0 & 1560 & $>10: 1$ \\
\hline
\end{tabular}

${ }^{a}$ Conditions: $\mathrm{CO} / \mathrm{H}_{2}=1, P\left(\mathrm{CO} / \mathrm{H}_{2}\right)=20$ bar, ligand $/ \mathrm{Rh}=5$, substrate $/ \mathrm{Rh}=637$,

$[\mathrm{Rh}]=1.00 \mathrm{mM}$, number of experiments $=3$. In none of the experiments, hydrogenation was observed.

${ }^{b}$ Natural bite angles taken from Ref. [20].

${ }^{c}$ Linear-to-branched ratio and turnover frequency were determined at $20 \%$ alkene conversion.

${ }^{d}$ Turnover frequency $=($ moles of aldehyde $)(\text { moles of } \mathrm{Rh})^{-1} \mathrm{~h}^{-1}$.

is considered, the ee/ea equilibrium in the hydride precursor is not the factor governing the regioselectivity when a smaller range of bite angles is considered. The $\mathrm{RhH}$ (diphosphine) $(\mathrm{CO})_{2}$ species itself is not involved in the step that determines the selectivity, but the selectivity is determined in the alkene coordination to $\mathrm{RhH}$ (diphosphine)(CO) or in the hydride migration step. A plausible explanation of the bite angle effect is that in these steps, an augmentation of the steric congestion around the metal center is produced when the bite angle is increased. This favors the sterically less demanding transition state of the possible ones, driving the reaction toward the linear product. Later [11], this was quantified by means of an integrated molecular orbital/molecular mechanics method, using the two limiting examples in the bite angle in the xantphos series, homoxantphos $\mathbf{1}$ and benzoxantphos $\mathbf{9}$.

\subsection{3}

\section{Electronic Bite Angle Effect and Activity}

While the effect of the bite angle on selectivity in 1-octene hydroformylation (and styrene as well [2]) seems to be steric, the existence of a relationship between activity and bite angle in the hydroformylation reaction that can be easily deduced from the experiments done within the xantphos ligands family, might well have an electronic origin. An increase in the rate was found with the increasing bite angle (1-9), but ligand 10, having the widest bite angle, showed a sharp increase in the rate of reaction (see Table 1.1).

The rate of dissociation of $\mathrm{CO}$ was studied separately via ${ }^{13} \mathrm{CO}$ exchange in a rapid scan IR spectroscopy study under pressure [16]. In this study, no influence of the natural bite angle on the rate of formation of the unsaturated (diphosphine) $\mathrm{Rh}(\mathrm{CO}) \mathrm{H}$ complexes was found for ligands 2,4 , and $\mathbf{6}$. Ligand $\mathbf{1 0}$ shows a sharp increase in CO 
<smiles>CC(C)(C)c1cc(P2c3ccccc3Oc3ccccc32)c2c(c1)P1c3ccccc3OC(C)(C)c3cc(C(C)(C)C)cc1c3O2</smiles>

dissociation rate (seven times that of the other ligands). As steric effects on $\mathrm{CO}$ coordination are supposed to be small, this was explained by assuming a larger stabilization of the four-coordinate intermediate for ligand $\mathbf{1 0}$ with a wider bite angle and more electron-withdrawing character.

In a series of electronically distinct but sterically equal ligands 4 , it was found that the overall selectivity for linear aldehyde was constant, whereas the linear branched ratio and the rate increased concomitantly with the ee/ea ratio in the hydrido isomers (Table 1.2) [20]. The higher $1 / \mathrm{b}$ ratio was because of an increase in the 2-octene formation - the "escape" route for the formed branched alkylrhodium intermediate.

It is possible that increasing the bite angle increases the activation energy for alkene coordination on steric grounds. What kind of electronic effect the widening of the bite angle has on the activation energy for alkene coordination depends on the dominant type of the alkene bonding; if electron donation from alkene to rhodium dominates, alkene coordination will be enhanced by wide bite angles.

In summary, a wider bite angle increases the concentration of unsaturated (diphosphine) $\mathrm{Rh}(\mathrm{CO}) \mathrm{H}$ and, other effects being absent or insignificant, the overall effect will result in an acceleration of the hydroformylation reaction.

When the backbone of a ligand allows both ee and ea coordination, the basicity of the phosphine has a pronounced effect on the chelation mode [22]. One of the first

Table 1.2 1-Octene hydroformylation using ligands $4 \mathbf{a}-\mathrm{g}^{a}$

\begin{tabular}{lllllll}
\hline Ligand & $\mathbf{R}^{\prime}$ & ee: ea ratio & l/b ratio $^{\boldsymbol{b}}$ & \% linear aldehyde & \% isomer & tof $^{\boldsymbol{b}, \boldsymbol{c}}$ \\
\hline 4a & $\mathrm{N}^{\boldsymbol{b}}\left(\mathrm{CH}_{3}\right)_{2}$ & $47: 53$ & 44.6 & 93.1 & 4.8 & 28 \\
$\mathbf{4 b}$ & $\mathrm{OCH}_{3}$ & $59: 41$ & 36.9 & 92.1 & 5.3 & 45 \\
$\mathbf{4 c}$ & $\mathrm{CH}_{3}$ & $66: 34$ & 44.4 & 93.2 & 4.7 & 78 \\
$\mathbf{4 d}$ & $\mathrm{H}$ & $72: 28$ & 50.0 & 93.2 & 4.9 & 110 \\
$\mathbf{4 e}$ & $\mathrm{F}$ & $79: 21$ & 51.5 & 92.5 & 5.7 & 75 \\
$\mathbf{4 f}$ & $\mathrm{Cl}$ & $85: 15$ & 67.5 & 91.7 & 6.9 & 66 \\
$\mathbf{4 g}$ & $\mathrm{CF}_{3}$ & $92: 8$ & 86.5 & 92.1 & 6.8 & 158 \\
\hline
\end{tabular}

\footnotetext{
${ }^{a}$ Data taken from Ref. [20]. $\mathrm{R}=p-\mathrm{C}_{6} \mathrm{H}_{4} \mathrm{R}^{\prime}$. Conditions: $\mathrm{CO} / \mathrm{H}_{2}=1, P\left(\mathrm{CO} / \mathrm{H}_{2}\right)=20$ bar, ligand/ $\mathrm{Rh}=5$, substrate $/ \mathrm{Rh}=637,[\mathrm{Rh}]=1.00 \mathrm{mM}$, number of experiments $=3$.

${ }^{b}$ Linear-to-branched ratio and turnover frequency were determined at $20 \%$ alkene conversion.

${ }^{c}$ Turnover frequency $=($ moles of aldehyde $)(\text { moles of } \mathrm{Rh})^{-1} \mathrm{~h}^{-1}$.
} 
systematic studies using diphosphines was by Unruh [23] who used substituted dppf. Both rate and selectivity increase when the $\chi$-value of the ligands increase. There are two possible reasons: electron's preference for linear alkyl complex formation when the $\pi$-back-donation to the phosphine increases; or, alternatively, EWD ligands enhance the formation of ee isomer as was observed later in the xantphos complexes [20]. This can be explained by the general preference of electron-withdrawing ligands for the equatorial positions in trigonal bipyramidal complexes. The loss of $\mathrm{CO}$ is faster for complexes containing ligands with higher $\chi$-values. As mentioned above, a stronger complexation of the alkene donor ligand may be expected for more electron-deficient rhodium complexes. Thus, higher rates can be explained because in most phosphine-based systems the step involving replacement of CO by alkene contributes to the overall rate. The reaction rate is first order in alkene concentration and -1 in $\mathrm{CO}$ in many catalyst systems.

The introduction of electron-withdrawing substituents on the aryl rings of the bisequatorial chelate of (BISBI) $\mathrm{RhH}(\mathrm{CO})_{2}$ leads to an increase in linear aldehyde selectivity as well as the rate. This must be an electronic effect on the $1 / b$ ratio since BISBI containing phenyl substituents coordinates already purely in the bis-equatorial fashion [15].<smiles>c1ccc(P(Oc2ccccc2-c2ccccc2OP(c2ccccc2)c2ccccc2)c2ccccc2)cc1</smiles>

11

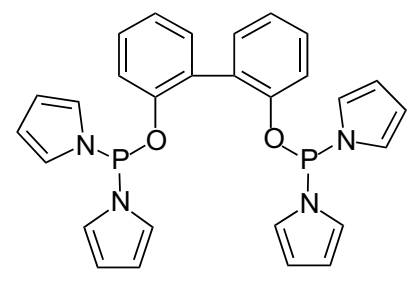

12

A similar electronic effect has been observed for ligands 11 and 12. Both coordinate exclusively in the ee mode in rhodium hydrido dicarbonyl; but for the electronwithdrawing ligand 11, a moderate $1 / \mathrm{b}$ ratio of 6 was found while that for the electronpoor ligand 12 was as high as 100 . Increased $1 / b$ ratios at higher $\chi$-values are relatively general for ligand effects in hydroformylation, but in the last cases they cannot be assigned to an electronic bite angle effect and they must represent an electronic effect per se, which is not fully understood yet [12].

\subsection{4}

\section{Isotope Effects [24]}

The above studies still left open the possibility of two steps that could be rate determining: alkene coordination or insertion in the rhodium hydride bond. To this end, the rate-determining step in the hydroformylation of 1-octene, catalyzed by the rhodium-xantphos catalyst system, was determined using a combination of experimentally determined ${ }^{1} \mathrm{H} /{ }^{2} \mathrm{H}$ and ${ }^{12} \mathrm{C} /{ }^{13} \mathrm{C}$ kinetic isotope effects and a theoretical approach. From the relative rates of hydroformylation and deuterioformylation of 1-octene, a small ${ }^{1} \mathrm{H} /{ }^{2} \mathrm{H}$ isotope effect of 1.2 was determined on the hydride moiety of the rhodium catalyst. ${ }^{12} \mathrm{C} /{ }^{13} \mathrm{C}$ isotope effects for the olefinic carbon atoms 
of 1-octene were determined at natural abundance. Both quantum mechanics/ molecular mechanics $(\mathrm{QM} / \mathrm{MM})$ and full quantum mechanics calculations were carried out on the key catalytic steps, using "real-world" ligand systems. The combination of kinetic isotope effects determination and theoretical studies suggest that the barrier for hydride migration has a slightly higher free energy than that of the alkene insertion under these conditions. Dissociation of CO constitutes the main part of the overall energy barrier, as is quite common in catalysis.

\section{3}

\section{Platinum-Catalyzed Alkene Hydroformylation}

Phosphine platinum complexes give active hydroformylation catalysts and both terminal and internal alkenes can be hydroformylated by selectively employing platinum-diphosphine complexes, often activated by an excess of tin chloride as the cocatalyst $[25,26]$. The combination of platinum chloride and tin(II) chloride leads to the formation of the trichlorostannate anion, which presumably acts as a weak coordinating anion, as tin-free catalyst systems have also been reported [27]. The group of Vogt found that the preformation of the catalyst also proved to be effective with only one equivalent of the tin source [28].

These systems have mainly been applied to asymmetric hydroformylation [29], although their strength in normal alkene hydroformylation rests in their high selectivity for linear aldehyde.

In platinum/tin-catalyzed hydroformylation, widening of the natural bite angle of the diphosphine ligands has proven to be favorable for the catalytic performance [21,25]. The synthesis of the (mixed) group 15 derivatives of the di-t-butyl-xantphos backbone, including the arsine-analogues of xantphos 13, has been explored. Xantarsine and xantphosarsine ligands $\mathbf{1 4}$ and $\mathbf{1 5}$ constituted the first efficient arsine modified platinum/tin catalysts for selective hydroformylation of terminal alkenes [30].<smiles>CC(C)(C)c1cc(P)c2c(c1)C(C)(C)c1cc(C(C)(C)C)cc(P)c1O2</smiles>

13<smiles>CC(C)(C)c1cc([AsH2])c2c(c1)C(C)(C)c1cc(C(C)(C)C)cc(-c3ccccc3)c1O2</smiles>

15

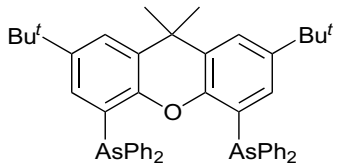

14<smiles>Pc1cccc2c1CCc1cccc(P)c1O2</smiles>

16

The calculated natural bite angles of ligands $13,14,15$, and 16 are $110^{\circ}, 113^{\circ}, 111^{\circ}$, and $102^{\circ}$, respectively. Ligands $\mathbf{1 3}-\mathbf{1 6}$ were tested in the platinum/tin-catalyzed hydroformylation (Table 1.3). In the hydroformylation of 1-octene, the arsine-based ligands 14 and $\mathbf{1 5}$ proved to give more efficient catalysts than the parent xantphos ligand $\mathbf{1 3}$. The 
Table 1.3 Platinum/tin-catalyzed hydroformylation of 1-octene at $60^{\circ} \mathrm{C}^{a}$

\begin{tabular}{|c|c|c|c|c|}
\hline Ligand & l/b ratio ${ }^{b}$ & $\% n$-nonanal ${ }^{b}$ & $\%$ isomerization $^{b}$ & tof $^{b, c}$ \\
\hline 13 & 230 & 95 & 4.5 & 18 \\
\hline 14 & $>250$ & 92 & 8.0 & 210 \\
\hline 15 & 200 & 96 & 3.1 & 350 \\
\hline 16 & $>250$ & 88 & 12 & 720 \\
\hline
\end{tabular}

${ }^{a}$ Reactions were carried out in a $180-\mathrm{ml}$ stainless steel autoclave in dichloromethane at $60^{\circ} \mathrm{C}$ under 40 bar of $\mathrm{CO} / \mathrm{H}_{2}(1: 1)$, catalyst precursor $\left[\mathrm{Pt}(\operatorname{cod}) \mathrm{Cl}_{2}\right]$, [Pt] $=2.5 \mathrm{mM}, \mathrm{Pt}: \mathrm{SnCl}_{2}: \mathrm{P}: 1$ octene $=1: 2: 4: 255$.

${ }^{b}$ Determined by GC with decane as the internal standard.

${ }^{c}$ Averaged turnover frequencies (tof) were calculated as (moles of aldehyde) (moles of Pt) ${ }^{-1} \mathrm{~h}^{-1}$ at $20-30 \%$ conversion.

xantarsine ligand 14 is only slightly less selective than xantphos 13, but it is more than 10 times as active. The xantphosarsine ligand 15 is even 20 times as active as xantphos 13, while displaying the same excellent selectivity for linear aldehyde formation.

Comparison of the activities of the xantphos ligands 13 and 16 revealed a dramatic effect of the natural bite angle. Narrowing the natural bite angle from $110^{\circ}$ to $102^{\circ}$ results in a 40-fold higher hydroformylation rate. The high selectivities of ligands 13 , 14, and 15 compared to xantphos 16 can be ascribed to the wider natural bite angles of the former ligands. Widening of the bite angle of the ligand will increase the steric congestion around the platinum center resulting in more selective formation of the sterically less hindered linear aldehydes.

\section{4}

\section{Palladium-Catalyzed CO/Ethene Copolymerization}

\subsection{1}

\section{Polyketone Formation}

One of the most astonishing manifestations of the dependence of a catalytic reaction on the bite angle of chelating diphosphines is the subtle balance between $\mathrm{CO} /$ alkene copolymerization and alkoxycarbonylation of alkenes (Scheme 1.3) [5,6]. Ethenepropene-CO polymers were produced commercially for a short while, oligomers have been studied as starting materials for resinlike materials, and methyl propanoate has been commercialized by Lucite and it is the starting material for making methyl methacrylate. In fact, methyl propanoate (product of the methoxycarbonylation of ethene) is the smallest possible product of the $\mathrm{CO} /$ ethene copolymerization using

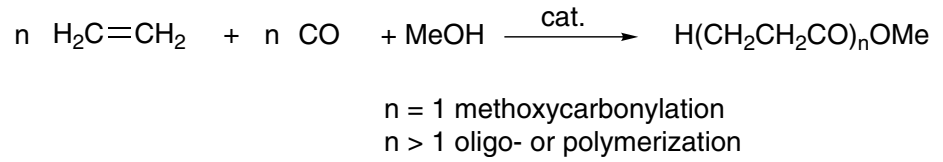

Scheme 1.3 Scheme of alkoxycarbonylation and $\mathrm{CO} /$ ethene copolymerization. 
methanol as the chain transfer agent. It is formed when chain transfer occurs immediately after the insertion of just two monomers. Consequently, the selectivity control between copolymerization and alkoxycarbonylation implies a tuning between chain propagation and chain transfer rates, which can be directed by modifications in the ligands.

Sen reported in the early 1980 s that certain $\mathrm{Pd}(\mathrm{II})-\mathrm{PPh}_{3}$ complexes containing weak coordinating anions (i.e., $\left.\left[\mathrm{Pd}\left(\mathrm{CH}_{3} \mathrm{CN}\right)_{4}\right]\left[\mathrm{BF}_{4}\right]_{2} \cdot n \mathrm{PPh}_{3}, n=1-3\right)$ produce oligomers $\left(25^{\circ} \mathrm{C}, 4-1.5\right.$ bar $)$ [31]. Weakly coordinating anions improve the productivity probably because they create easily accessible coordination sites; this also explains the lower activity obtained when a large excess of $\mathrm{PPh}_{3}$ was used.

In the same year, Drent (Shell), when studying the alkoxycarbonylation reaction in methanol by using palladium complexes similar to those used by Sen, discovered that replacing the excess of $\mathrm{PPh}_{3}$ by a stoichiometric amount of diphosphine generates catalysts for the polymerization reaction that are orders of magnitude faster [32]. Using these complexes, $\mathrm{PdX}_{2}(\mathrm{~L} \cap \mathrm{L})(\mathrm{L} \cap \mathrm{L}$ being a bidentate phosphorus or nitrogen ligand chelating in a cis fashion, $\mathrm{X}$ a weak coordinating anion), perfectly alternating $\mathrm{CO} /$ ethene copolymer was produced with only ppm quantities of residual catalyst. Suitable ligands were coordinating diphosphines (i.e., dppe, dppp, and dppb). The number of carbon atoms in the backbone showed to have a dramatic influence on the activity and selectivity (see Table 1.4) [33].

The change of selectivity from alkoxycarbonylation to oligomerization or polymerization when changing from monophosphines to chelating diphosphines was first rationalized in terms of a bite angle effect [33]. With monophosphines, a trans orientation of the phosphine ligands is more stable for the acyl or alkyl species. Therefore, immediately after an insertion, a cis-trans isomerization occurs. The new species formed opposes further insertions and chain growth. Thus, the acylpalladium species will eventually terminate by alcoholysis of the Pd-acyl bond,

Table 1.4 Palladium-catalyzed $\mathrm{CO} / \mathrm{C}_{2} \mathrm{H}_{4}$ copolymerization: the effect of variation of the chain length of bidentate phosphines. ${ }^{a}$

\begin{tabular}{lllc}
\hline Ligand $\mathbf{P h}_{\mathbf{2}} \mathbf{P}\left(\mathbf{C H}_{\mathbf{2}}\right)_{\boldsymbol{m}} \mathbf{P P h}$ & $\left.\boldsymbol{\beta}_{\mathbf{n}}{ }^{\boldsymbol{b}}{ }^{{ }}\right)$ & Product $^{\boldsymbol{c}} \mathbf{H}\left(\mathrm{CH}_{\mathbf{2}} \mathbf{C H}_{\mathbf{2}} \mathbf{C O}\right)_{\mathbf{n}} \mathbf{O C H}_{\mathbf{3}}$ & Reaction rate $^{\boldsymbol{d}}\left(\mathbf{g ~ g}^{-\mathbf{1}} \mathbf{P d ~ h}^{-\mathbf{1}}\right)$ \\
\hline$m=1$ & 72 & $\tilde{n}=2$ & 1 \\
2 & 85 & 100 & 1000 \\
3 & 91 & 180 & 6000 \\
4 & 98 & 45 & 2300 \\
5 & & 6 & 1800 \\
6 & & 2 & 5
\end{tabular}

\footnotetext{
${ }^{a}$ Data taken from Ref. [33]. Solvent $\mathrm{CH}_{3} \mathrm{OH}$, catalyst $\mathrm{Pd}\left(\mathrm{CH}_{3} \mathrm{CN}\right)_{2}(\mathrm{OTs})_{2}$, and diphosphine; $\mathrm{C}_{2} \mathrm{H}_{4} / \mathrm{CO}=1$; temperature $=84^{\circ} \mathrm{C}$; pressure $=45$ bar.

${ }^{b}$ Natural bite angles taken from Ref. [9].

${ }^{c}$ The average degree of polymerization $(\tilde{n})$ determined by end group analysis from ${ }^{13} \mathrm{C}$ NMR spectra, except for the low molecular weight products, where a combination of GC and NMR was used.

${ }^{d}$ The rate was the highest measured during the reaction period $(1-5 \mathrm{~h})$.
} 
which was initially thought to take place in the trans species [34]. When cis and trans isomers occur in equilibrium, this is reflected in a tendency to form oligomers.

However, when diphosphines are used, in which the phosphorus donor atoms are always cis to one another (all the ligands assayed were cis coordinating), the growing chain and monomer are in cis positions as well - a prerequisite for insertion reactions. As a result, diphosphines with natural bite angles close to $90^{\circ}$ (dppp) stabilize the transition state for insertion reactions (chain growth), explaining also the higher activity and polymer selectivity of dppp when compared to monophosphines. The trend for the bidentates in Table 1.4 together with those of other series of diphosphine ligands [35] will be discussed below. Later, this explanation for the difference between mono- and diphosphines has been reconsidered.

\subsection{2}

\section{Chain Transfer Mechanisms (Initiation-Termination)}

In the earliest publications [33], it was proposed that the initiation step in both hydroxycarbonylation and polymerization reactions involved the reaction of the alcohol with the palladium complex to give the catalytically active palladium-methoxy complexes. After chain growing reactions, the termination mechanism was supposed to proceed via protonolysis of the alkyl-palladium complex to give the ketoester (KE) product (methyl propanoate or polymer) and regenerate the active catalyst (Scheme 1.4). In addition, hydrido palladium species are smoothly formed from palladium(II) salts in methanol (not shown).

However, a GC analysis of the oligomeric fractions obtained when using dppb (1,4diphenylphosphinobutane) showed that although the ketone/ester end group ratio was close to 1, together with the KE polyketone, products containing diketo (KK) or diester (EE) end groups were also obtained. The appearance of these palindrome products cannot be explained via the catalytic cycle mentioned before. If only one chain transfer mechanism is active (one termination releasing the polymer and regenerating the initiation active species) via methanol reaction with the palladiumchain compound, it is not possible to obtain KK or EE products in the absence of oxidants or reductants. To explain the formation of these products, the two different

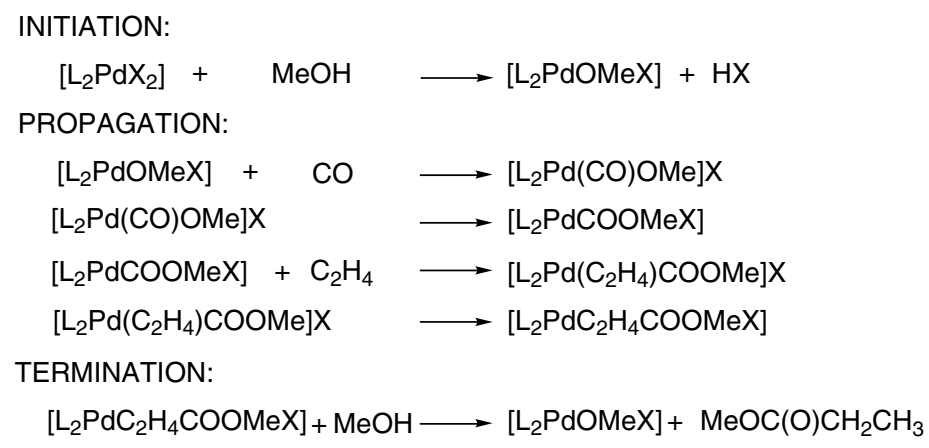

Scheme 1.4 Mechanism initially proposed for ethene hydroxycarbonylation. 
$12 \mid$

1 Bite Angle Effects of Diphosphines in Carbonylation Reactions

INITIATION A

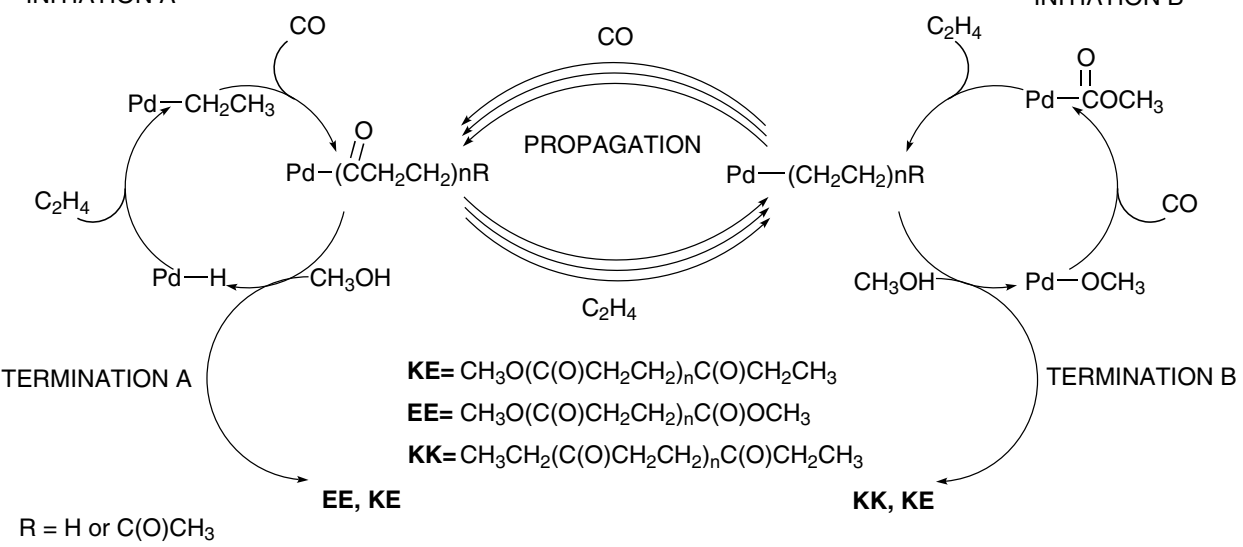

Scheme 1.5 Proposed catalytic cycle for $\mathrm{CO} /$ ethene polymerization.

chain-transfer mechanisms A and B (corresponding to Pd-hydride and the Pdmethoxy initiation species) must occur simultaneously (Scheme 1.5) [33]. When other ligands are used at lower temperatures and in the absence of reagents that can convert hydride species into methoxy species or vice versa, predominantly KE oligomers have been obtained.

The effect of the bite angle on the termination reaction has been the focus of recent studies. The mechanism B, involving the enolate formation [36], is only slightly sensitive to changes in the bidentate ligand (dppe, dppp, and dppf) and the reaction is slightly faster for ligands with a wider bite angle [36].

The effect of the bite angle on termination reaction A has also been studied recently on model acyl-palladium compounds containing a variety of bidentate phosphine ligands [37]. The reaction turned out to be extremely sensitive to the steric properties of the ligand and therefore to the bite angle also. From the results obtained so far, it was concluded that the dppp backbone (bite angle close to $90^{\circ}$ ) is decisive in obtaining high molecular weight polymers in $\mathrm{CO} /$ ethene copolymerization owing to electronic bite angle effects. We will return to this after we have introduced the catalysts that give methyl propanoate as the product. The use of bdompp (1,3-bis(di-(o-methoxyphenyl)phosphino)propane) gave a polymer of higher molecular weight than the one obtained with dppp [32,38]. This is not easily explained as, on the one hand, the ligand is somewhat more bulky than dppp, but the hemilabile methoxy groups, on the other hand, may participate in the coordination sphere of palladium, the effect of which is unknown. At this point of time, it seemed fair to conclude that [38] "Nowadays the catalyst selected for the manufacture of Carilon polymer at commercial scale is $\mathrm{Pd}(\mathrm{bdompp}) \mathrm{X}_{2}$. This catalyst is not only more active than the most prominent member of the first generation of CO-ethene copolymerization catalysts (dppp), but also produces coand terpolymers with a considerably higher molecular weight." In conclusion, the ligand chosen by the industry in the early 1990s showed a synergism between the electronic and steric bite angle effect. 


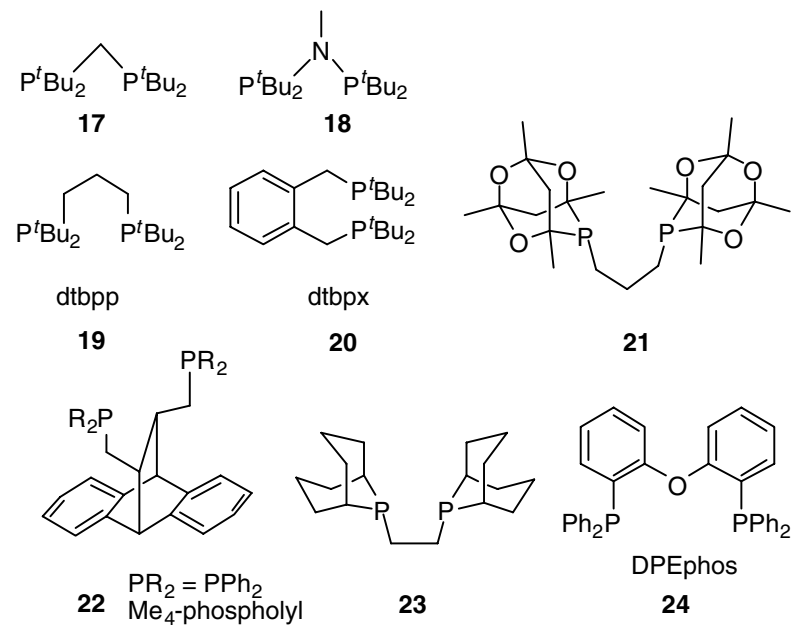

Not only the use of substituents at the phenyl groups at phosphorus, but also the introduction of groups attached to the backbone has been exploited. A study on dppp modified ligands showed that the introduction of alkyl substituents on the 2 position of the propane chain did not improve catalyst performance. In contrast, the productivity increased remarkably when methyl groups were introduced on 1 and 3 positions of the diphosphine ligand, the effect depending on the configuration of the stereogenic centers generated [39]. The same effect has been observed for 2,3substituted dppb derivatives [40]. Thus, a slight increase of the steric constraints leads to a faster catalyst, while the length of the backbone and the bite angle remains the same. Some mechanistic studies have also been developed to determine the origin of these steric effects [40]. Although a conclusive explanation is still lacking, it seems clear that beta chelates (with the oxygen of the acyl group occupying a coordination site) are resting states in the catalytic cycle [41]. A possible explanation could involve that the opening of the beta chelates via a five-coordinate transition state constitutes the rate-limiting step or a step close to it. This step could be strongly influenced by the steric environment of the metal center.

For a long time, it had been generally accepted that diphosphine ligands containing only one carbon atom in the backbone (dppm derivatives) do not generate active catalysts for CO/ethene oligomerization or polymerization (Table 1.4). An important observation is that ligands $\mathbf{1 7}$ and $\mathbf{1 8}$ with still larger substituents at phosphorus but a backbone that consists of just one atom gave highly active catalysts producing polymer. Recently, it has been reported that several dppm derivatives with various types of bulky groups on the phosphorus atoms form active catalysts for polyketone synthesis, whereas the dppm ligand under the same reaction conditions shows lower productivities [42]. Thus, neither the bite angle nor the flexibility of the backbone is a prerequisite for making a polymer; instead it would seem that a certain steric bulk around the palladium site is required that tunes the reactivity for insertion and termination reactions and also reduces the amount of catalyst residing in one of the inactive resting states. The latter is usually neglected, but it surely is of great importance in palladium catalysis. 


\subsection{3}

\section{Methyl Propanoate Formation}

By introducing steric modifications on the ligand maintaining the propane backbone, it is possible to radically change the selectivity. Drent reported that the use of dtbpp, 19, a bidentate in which tertiary butyl groups replace the phenyl groups in dppp, changes the selectivity of the catalyst completely from polyketone to methyl propanoate [43]. Both the selectivity and the rate were further improved by slightly enlarging the backbone of the catalyst with the use of a xylene moiety [44]. In recent years, a whole range of bulky bidentate phosphine ligands have been added to the initial two examples all giving methyl propanoate, or mixtures with oligomers, with moderate-to-high rates (21 [45], 22 [46], 23 [47], and 24 [37]). For the fast catalyst systems such as those based on $\mathbf{2 0}$, it has been proven that the catalytic cycle follows the hydride mechanism A (Scheme 1.5).

Another example in which backbone substitution affords the effect of increasing steric bulk is provided by octamethyl-dppf, carrying eight methyl substituents at the ferrocene rings [48]. While dppf gives oligomers in the methoxycarbonylation/ polyketone reaction (rate $5000 \mathrm{~mol} \mathrm{~mol}^{-1} \mathrm{~h}^{-1}$, at $85^{\circ} \mathrm{C}$ ), octamethyl-dppf gave methyl propanoate. Octamethyl-dppf is sterically more crowded albeit not via substitution directly at the phosphorus atoms, as appears from the $\mathrm{P}-\mathrm{Pd}-\mathrm{P}$ angle, which is $101^{\circ}$ as compared to $96^{\circ}$ for $\mathrm{dppf}$ in the dicationic palladium diaqua adducts. Indeed, octamethyl-dppf gives methyl propanoate in the palladium-catalyzed reaction with ethene, $\mathrm{CO}$, and $\mathrm{CH}_{3} \mathrm{OH}$, albeit at a modest rate $\left(600 \mathrm{~mol} \mathrm{~mol}^{-1} \mathrm{~h}^{-1}\right.$, at $\left.85^{\circ} \mathrm{C}\right)$.

DPEphos, 24, gave methyl propanoate at a rate of $2000 \mathrm{~mol} \mathrm{~mol}^{-1} \mathrm{~h}^{-1}$, at $80^{\circ} \mathrm{C}$ and 20 bar, and an additional $10 \%$ of the lowest oligomer [37]. Surprisingly, xantphos, $\mathbf{5}$, gave hardly any activity in this reaction. Xantphos can form trans complexes, which remain inactive in this type of catalytic reactions $[7,49]$ - not unexpectedly, as insertion reactions require a cis disposition of the migrating group and unsaturated fragment.

When the $t$-butyl groups were replaced by the smaller $i$-propyl groups in 19 [50] or 20 [44], both systems produced oligomers at high rates instead of methyl propanoate. When the 1,3-propanediyl bridge in $(t-\mathrm{Bu})_{2} \mathrm{P}\left(\mathrm{CH}_{2}\right)_{3} \mathrm{P}(t-\mathrm{Bu})_{2}$ was replaced by a 1,2-ethanediyl bridge, the accessibility of the catalyst for ethene increased so that in the reaction of ethene, $\mathrm{CO}, \mathrm{CH}_{3} \mathrm{OH}$, and $\mathrm{H}_{2}$ pentan-3-one was formed at extremely high rates instead of methyl propanoate, the product of the more bulky ligand.

From the data of the last decade emerges a new picture of the effect of the steric bulk. Clearly, starting from dppe, continuing with dppp and then on with still larger ligands, the overall rate of polymer production increases, which can be attributed to the destabilization of resting states preceding the insertion of ethene, the rate-determining step. However, at a certain point this relationship is broken, perhaps by hampering the coordination of ethene altogether to the intermediate palladium-acyl species. Instead, methanol coordination and reductive elimination take place (see Section 1.4.4). Most interestingly, the termination reaction not only becomes faster in the bulky catalysts relative to propagation, but, also, in absolute terms it becomes orders of magnitude faster [37] with increasing steric bulk of the ligand. The first insertion of ethene in the methyl propanoate forming reaction is much less sensitive to changes in 
the ligand bulk, because this takes place at a palladium hydrido species, as has been proven for a few bidentate ligands [51] and monodentate phosphine catalysts [34,52].

Previously, the formation of methyl propanoate has been associated with trans complexes generated by monodentate ligands. Indeed, trans acyl complexes are the resting states of these catalytic systems [6,34]. Following this explanation, an "arm-off" mechanism for the strained bidentates such as 19-24 could be imagined replacing the phosphine trans to acyl also with a solvent molecule. Recent measurements have shown that this is not the case and that the alcoholysis reaction requires cis orientation for the acyl group and the alcohol, and thus a cis-diphosphine [37]. The decisive factor is the steric hindrance exerted by the ligand: the larger the steric bulk, the faster the ester formation. For monodentate ligands such as $\mathrm{PPh}_{3}$, the trans complexes undergo an isomerization to a cis complex, which behaves effectively as a complex containing a bulky bidentate, and then the sequence of reactions is terminated by alcoholysis; however, the catalyst is slower than a bulky cis bidentate as the complex resides mainly in the nonactive trans configuration. Thus, we arrive at the conclusion that in both the polymerization and the methoxycarbonylation reaction, all data point to merely steric causes.

\subsection{4}

\section{Theoretical Support}

A recent DFTstudy gave further insight into the effects of ligands on various insertion and elimination steps [53]. Both chain propagation and methanolysis termination mechanisms catalyzed by palladium complexes containing electron-donating diphosphine ligands were studied. The rate-determining step in the chain propagation mechanism is the insertion of ethene into the palladium-ethanoyl bond, yielding a $\beta$-chelate complex of the formed keto group. For the methanolysis pathways, the formation of a 14-electron intermediate is crucial, because unlike the formation of $\mathrm{CO}$ an ethene complexes, which occur through associative ligand exchange processes, methanol coordination requires a vacant site. The calculations show that the most likely methanolysis pathway involves a proton transfer/reductive elimination mechanism, in which the solvent acts as a proton transfer agent.

Both increasing the bite angle and increasing the steric bulk of the diphosphine ligand stabilize the 14-electron $\eta^{2}$-acyl complex. Increasing the steric bulk of the ligand strongly disfavors the formation of ethene complex and consequently increases the barrier for ethene insertion, as expected.

For all methanolysis pathways considered in this study, increasing the bite angle of the diphosphine ligand increases the rate of methanolysis. This is attributed to the involvement of electron-rich intermediates and/or transition states in all three methanolysis pathways.

The steric bulk of the diphosphine ligand hardly affects the barriers for methanolysis via the stepwise and concerted reductive elimination pathways. Based on these observations, it was postulated that the high activity and chemoselectivity in the methoxycarbonylation of ethene observed for $t$-butyl substituted wide bite angle diphosphine ligands are determined by a combination of electronic and steric effects induced by the diphosphine ligand. The high electron density at the metal center 
induced by the s-donating diphosphine ligand stabilizes 14-electron $\eta^{2}$-acyl intermediate, while suppressing the formation of 18-electron intermediates such as ethene complex. Methanol coordination is hardly affected by the steric bulk of the ligand, although increasing steric bulk of the ligand enhances the direct nucleophilic attack of methanol on $\eta^{2}$-acyl complex. Furthermore, for all methanolysis pathways considered, the barrier for the formation of the ester product decreases when the bite angle of the diphosphine ligand increases. This is attributed to the formation of zerovalent palladium complexes, which are stabilized by wide bite angle ligands [10].

\section{5}

\section{Rhodium-Catalyzed Methanol Carbonylation: the Ligand-Modified Monsanto Process}

Acetic acid is a bulk commodity whose actual annual global production reaches 8 million tons, led by two companies, Celanese (using "Monsanto" technology) and BP Chemicals, with processes based on both rhodium and iridium [54]. Methanol carbonylation, from an economic point of view, presents a clear advantage over all the former processes developed for the industrial production of acetic acid. Methanol and $\mathrm{CO}$ are relatively cheap feedstocks that can be obtained from different raw materials, which makes the whole process independent of petroleum prices. Methanol can be obtained from syngas ( $\mathrm{CO}$ and $\mathrm{H}_{2}$ mixture) coming from petroleum, natural gas, or even from coal or biomass. These latest technologies are not yet onstream, but industries are considering them as powerful candidates for the future and pilot plants operate since the mid-1990s [55].

The process presents a $100 \%$ atom economy with all the atoms in the reactants going into the product (see Equation 1.1), and compared to previous methods benefits of a reduced waste and easier (and cheaper) product separation.

$$
\mathrm{CH}_{3} \mathrm{OH}+\mathrm{CO} \rightarrow \mathrm{CH}_{3} \mathrm{COOH} \quad \Delta G^{\circ}=-75 \mathrm{~kJ} \mathrm{~mol}^{-1}, \Delta H^{\circ}=-135 \mathrm{~kJ} \mathrm{~mol}^{-1} .
$$

From the early beginning, a lot of effort was devoted to elucidate the reaction mechanism, and the key steps of the catalytic cycle are nowadays well established (see Figure 1.1). The rate-limiting step is the oxidative addition of $\mathrm{CH}_{3} \mathrm{I}$ to the $\mathrm{Rh}(\mathrm{I})$ species, as kinetic studies showed first-order dependence on $\mathrm{CH}_{3} \mathrm{I}$ and $\mathrm{Rh}$ precursor and zero order on $\mathrm{CO}$ and $\mathrm{CH}_{3} \mathrm{OH}$.

Although the rhodium-catalyzed processes currently onstream are based on the original rhodium iodide Monsanto system (no ligands added), in the last 20 years many reports deal with the use of phosphines (and other ligands) to tune the catalyst properties. A general approach to facilitate the oxidative addition of $\mathrm{CH}_{3} \mathrm{I}$ to the active rhodium species, and therefore to enhance the rate of the overall process, is to increase the nucleophilicity of the metal center. This is accomplished by substituting $\mathrm{CO}$ and $\mathrm{I}^{-}$for stronger donor ligands. In most of the cases, either chelating or two donating ligands are used, and a neutral $[\mathrm{Rh}(\mathrm{L})(\mathrm{CO}) \mathrm{I}](\mathrm{L}=$ chelating or two monodentate ligands) active species is generated. Ligand modified systems are aimed at 


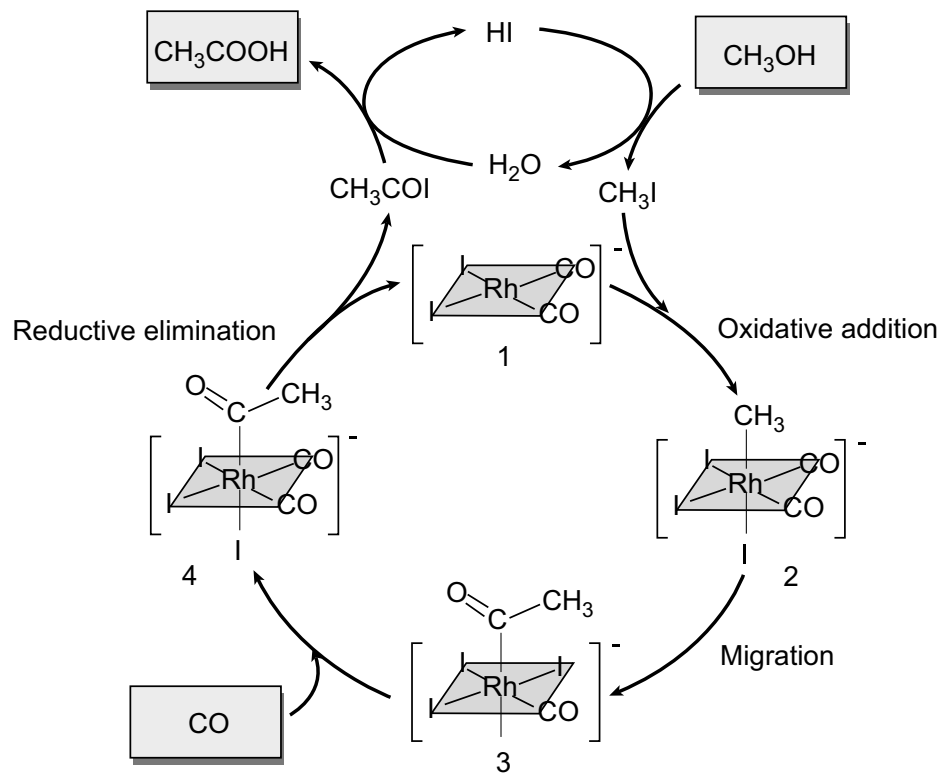

Figure 1.1 Monsanto catalytic cycle.

increasing not only the activity but also the selectivity and stability of the metal in the areas of low CO pressure (one of the main drawbacks of the process).

Even though several chelating diphosphines have been considered as likely ligands for this reaction (using the chelate effect to stabilize the ligand under the harsh conditions of the process), their performance has not traditionally been analyzed in terms of bite angle.

Only the recent patent literature [56,57] refers explicitly to the beneficial use of wide bite angle $\left(\beta>105^{\circ}\right)$ and rigid (flexibility range $\left.<40^{\circ}\right)$ diphosphines for this reaction (i.e., xantphos 5 and BISBI). They claim the positive effect of these ligands as related to the inhibition of side reactions leading to acetaldehyde and the corresponding undesired hydrogenation products (namely ethanol and its derivatives ethylmethylether and ethyl acetate). Acetaldehyde formation implies the existence of a complex containing a hydride and an acyl group in mutually cis positions. Owing to the postulated geometry of the rhodium-acyl species ([Rh $\left.(\mathrm{P} \cap \mathrm{P})\left(\mathrm{COCH}_{3}\right) \mathrm{I}_{2}\right]^{-}$with the acyl occupying the apical position of a pentacoordinated square base pyramid (sbp), AcH reductive elimination requires a concerted movement of ligands prior to or after $\mathrm{H}_{2}$ addition, as postulated for the related reductive methanol carbonylation reaction [58]. Although detailed calculations are still missing, the argument used is that a rigid ligand backbone should prevent the complex to easily change from the original sbp conformation avoiding hydrogenolysis of the metal-acyl species.

Using bite angle considerations this should be interpreted as a bite angle effect, where rigid wide bite angle diphosphines produce a destabilizing effect on the transition states required for the undesired side reaction to take place. Based on the 
Table 1.5 Methanol carbonylation using chelating diphosphines. ${ }^{a}$

Selectivity

\begin{tabular}{lcllllll}
\cline { 5 - 6 } Ligand & $\boldsymbol{\beta}\left({ }^{\circ} \mathbf{C}\right)$ & $\begin{array}{l}\text { Flexibility } \\
\text { range }\end{array}$ & $\begin{array}{l}\text { Reaction } \\
\text { time }(\mathbf{m i n})\end{array}$ & $\begin{array}{l}\mathrm{CH}_{3} \mathbf{O H} \\
\text { conversion (\%) }\end{array}$ & $\begin{array}{l}\text { HAcO and } \\
\text { derivatives }\end{array}$ & $\begin{array}{l}\text { EtOH } \\
\text { derivatives/AcH }\end{array}$ & $\mathbf{C H}_{\mathbf{4}}$ \\
\hline dppp $^{b}$ & 91 & $81-112$ & 30 & 38.8 & 28.1 & $1.2 / 42.9$ & 26.9 \\
dppp, $^{b}$ & 91 & $81-112$ & 120 & 16.8 & 20.0 & $42.7 / 15.3$ & 21.9 \\
Xantphos $^{b}$ & $111^{c}$ & $97-133^{d}$ & 21 & 29.2 & 38.3 & $0 / 0.3$ & 60.9 \\
Xantphos $^{b}$ & $111^{c}$ & $97-133^{d}$ & 17 & 31.1 & 35.7 & $2.6 / 0.5$ & 60.7 \\
BISBI $^{b}$ & $112^{e}$ & $92-155^{e}$ & 51 & 38.0 & 37.6 & $1.7 / 1.2$ & 59.3
\end{tabular}

Reaction conditions: $\left[\mathrm{Rh}(\mathrm{acac})(\mathrm{CO})_{2}\right](0.65 \mathrm{~g}, 2.5 \mathrm{mmol})$, ligand $2.8 \mathrm{mmol}, 80 \mathrm{~g} \mathrm{CH}_{3} \mathrm{OH}, 14 \mathrm{~g}$

$\mathrm{CH}_{3} \mathrm{I}, 140^{\circ} \mathrm{C}, 67-70$ bar syngas $\left(\mathrm{H}_{2}: \mathrm{CO}=2\right)$.

${ }^{a}$ Data extracted from Ref. [56].

${ }^{b} \mathrm{RuCl}_{3}$ approximately $10 \mathrm{mmol}$ as additive.

${ }^{c}$ Data extracted from Ref. [67].

${ }^{d}$ Data extracted from Ref. [16]

${ }^{e}$ Data extracted from Ref. [15].

same considerations, the coplanar terdentate coordination of xantphos derivatives $(\mathrm{P}-\mathrm{O}-\mathrm{P})$ in the corresponding acyl intermediates are also postulated as responsible for the superior performance of these derivatives when compared to other wide bite angle diphosphines (Table 1.5).

Another extreme bite angle effect was observed when trans-spanning diphosphines were used. When SPANphos ligands where studied in $\mathrm{CH}_{3} \mathrm{OH}$ carbonylation, kinetic experiments performed on the commonly accepted rate-

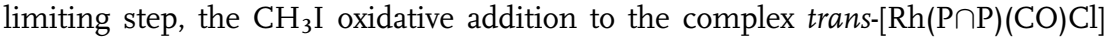
$(\mathrm{P} \cap \mathrm{P}=$ SPANphos derivatives), a complete inhibition of the reaction was observed [59]. Halogen exchange happened instead leading to trans- $[\mathrm{Rh}(\mathrm{P} \cap \mathrm{P})(\mathrm{CO}) \mathrm{I}]$. The same behavior has been observed for other diphosphanes that do not easily isomerize from trans to cis positions [60] and for ligands that even coordinating in a cis manner sterically block one of the axial sites of the metal [61].

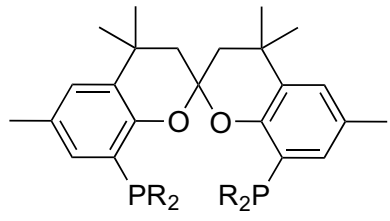

SPANphos
SPAN-PPh $\quad \mathrm{PR}_{2}=\mathrm{PPh}_{2}$

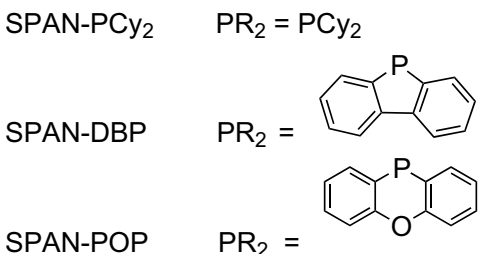

It is generally accepted that oxidative addition follows a two-step $\mathrm{S}_{\mathrm{N}} 2$ mechanism: nucleophilic attack by the metal on the methyl carbon to displace iodide, presumably 

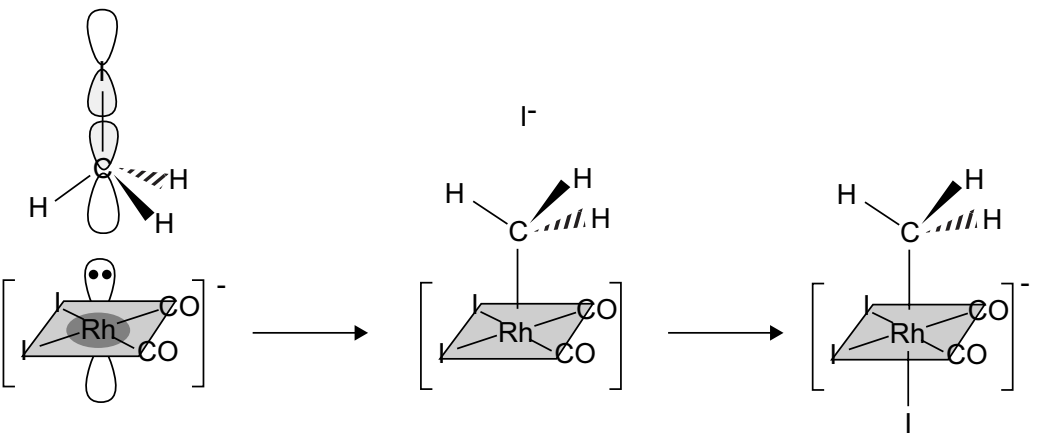

Figure 1.2 $\mathrm{S}_{\mathrm{N}} 2$ mechanism for $\mathrm{CH}_{3}$ I oxidative addition.

with inversion of configuration at the carbon atom, and a subsequent iodide coordination to the five-coordinate rhodium complex to give the alkyl complex 2 (Figure 1.2) [62]. When considering the bare rhodium (Monsanto) system, the product of this reaction has been fully characterized spectroscopically [63]. Although there is general agreement on the mechanism, the theoretical calculations with respect to the geometry of the TS are still controversial [64], but the main interaction in the $\mathrm{Rh}-\mathrm{C}$ bond formation seems to take place between a full metal $\mathrm{d}_{z^{2}}$ orbital and an empty $\mathrm{C}-\mathrm{I} \sigma *$ orbital.

The complete inhibition of $\mathrm{CH}_{3} \mathrm{I}$ oxidative addition observed in the case of trans chelating diphosphines complexes has been attributed to the fact that one of the axial sites of the rhodium center is blocked by the ligand backbone, avoiding the $\mathrm{CH}_{3} \mathrm{I}$ addition to proceed (Figure 1.3).

Surprisingly, when SPANphos derivatives [59] and other trans chelating diphosphines [65] were tested as ligands for rhodium-catalyzed methanol carbonylation, they showed to be one of the most active systems reported until now for this reaction. The observed activities (taking into account the complete absence $\mathrm{CH}_{3} \mathrm{I}$ oxidative addition to the presynthesized mononuclear trans species) have been attributed to the formation of active dinuclear species. Kinetic studies on the $\mathrm{CH}_{3} \mathrm{I}$ oxidative addition to presynthesized SPANphos dinuclear species of the form $\left[\mathrm{Rh}_{2}(\mathrm{SPANphos})(\mu-\mathrm{Cl})_{2}(\mathrm{CO})_{2}\right]$ showed fast reaction rates $\left(k_{1}=0.025 \mathrm{~s}^{-1}\right.$ $\mathrm{M}^{-1}$ ), but the mechanism operating under catalytic conditions is being investigated [66].
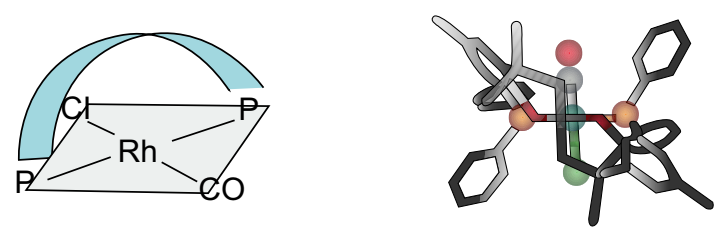

Figure 1.3 $[\mathrm{Rh}(\mathrm{SPANphos})(\mathrm{CO}) \mathrm{Cl}]$ complex (X-ray structure). 
$20 \mid 1$ Bite Angle Effects of Diphosphines in Carbonylation Reactions

\section{References}

1 Devon, T.J., Phillips, G.W., Puckette, T.A., Stavinoha, J.L. and Vanderbilt, J.J. (1987) Chelate Ligands for Low Pressure Hydroformylation Catalyst and Process Employing Same, Eastman Kodak Company.

2 Kranenburg, M., van der Burgt, Y.E.M., Kamer, P.C.J. and van Leeuwen, P.W.N.M. (1995) New diphosphine ligands based on heterocyclic aromatics inducing very high regioselectivity in rhodium-catalyzed hydroformylation: effect of the bite angle. Organometallics, 14, 3081.

3 Casey, C.P. and Whiteker, G.T. (1990) The natural bite angle of chelating dipho-sphines. Israel Journal of Chemistry, 30, 299.

4 Goertz, W., Kamer, P.C.J., van Leeuwen, P. W.N.M. and Vogt, D. (1997) Application of chelating diphosphine ligands in the nickelcatalysed hydrocyanation of alk-1-enes and omega-unsaturated fatty acid esters. Journal of the Chemical Society, Chemical Communications, 1521.

5 Freixa, Z. and van Leeuwen, P.W.N.M. (2003) Bite angle effects in diphosphine metal catalysts: steric or electronic? Journal of the Chemical Society, Dalton Transactions, 1980.

6 van Leeuwen, P.W.N.M., Kamer, P.C.J., Reek, J.N.H. and Dierkes, P. (2000) Ligand bite angle effects in metal-catalyzed $\mathrm{C}-\mathrm{C}$ bond formation. Chemical Reviews, 100, 2741.

7 Kamer, P.C.J., van Leeuwen, P.W.N.M. and Reek, J.N.H. (2001) Wide bite angle diphosphines: xantphos ligands in transition metal complexes and catalysis. Accounts of Chemical Research, 34, 895.

8 Kamer, P.C.J., Reek, J.N.H. and van Leeuwen, P.W.N.M. (1998) Designing ligands with the right bite. Chemtech, 28, 27.

9 Dierkes, P. and van Leeuwen, P.W.N.M. (1999) The bite angle makes the difference: a practical parameter for diphosphine ligands. Journal of the Chemical Society, Dalton Transactions, 1519.
10 Zuidema, E., van Leeuwen, P.W.N.M. and Bo, C. (2005) Reductive elimination of organic molecules from palladium-diphosphine complexes. Organometallics, 24, 3703.

11 Carbó, J.J., Maseras, F., Bo, C. and van Leeuwen, P.W.N.M. (2001) Unraveling the origin of regioselectivity in rhodium diphosphine catalyzed hydroformylation. A DFT QM/MM study. Journal of the American Chemical Society, 123, 7630.

12 van der Slot, S.C., Duran, J., Luten, J., Kamer, P.C.J. and van Leeuwen, P.W.N.M. (2002) Rhodium-catalyzed hydroformylation and deuterioformylation with pyrrolylbased phosphorus amidite ligands: influence of electronic ligand properties. Organometallics, 21, 3873.

13 Pacciello, R. (2007) private communication. 14 van Rooy, A., Goubitz, K., Fraanje, J., Kamer, P.C.J., van Leeuwen, P.W.N.M., Veldman, N. and Spek, A.L. (1996) Bulky diphosphitemodified rhodium catalysts: hydroformylation and characterization. Organometallics, 15, 835; Broussard, M.E., Juma, B., Train, S.G., Peng, W.J., Laneman, S.A. and Stanley, G.G. (1993) A bimetallic hydroformylation catalyst: high regioselectivity and reactivity through homobimetallic cooperativity. Science, 260, 1784; van der Veen, L.A., Kamer, P.C.J. and van Leeuwen, P.W.N.M. (1999) Hydroformylation of internal olefins to linear aldehydes with novel rhodium catalysts. Angewandte Chemie-International Edition in English, 38, 336.

15 Casey, C.P., Whiteker, G.T., Melville, M.G., Petrovich, L.M., Gavney, J.A., Jr, and Powell, D.R. (1992) Diphosphines with natural bite angles near $120^{\circ}$ increase selectivity for $n$ aldehyde formation in rhodium-catalyzed hydroformylation. Journal of the American Chemical Society, 114, 5535.

16 van der Veen, L.A., Keeven, P.H., Schoemaker, G.C., Reek, J.N.H., Kamer, P.C.J., van Leeuwen, P.W.N.M., Lutz, M. and Spek, A.L. (2000) Origin of the bite 
angle effect on rhodium diphosphine catalyzed hydroformylation.

Organometallics, 19, 872.

17 Heck, R.F. and Breslow, D.S. (1961) Reaction of cobalt hydrotetracarbonyl with olefins. Journal of the American Chemical Society, 83, 4023; Heck, R.F. and Breslow, D.S. (1962) Acylcobalt carbonyls and their triphenylphosphine complexes. Journal of the American Chemical Society, 84, 2499.

18 Brown, J.M. and Kent, A.G. (1987) Structural characterisation in solution of intermediates in rhodium-catalysed hydroformylation and their interconversion pathways. Journal of the Chemical Society, Perkin Transactions 2, 1597.

19 Hughes, O.R. and Unruh, J.D. (1981) Hydroformylation catalyzed by rhodium complexes with diphosphine ligands. Journal of Molecular Catalysis, 12, 71; Sanger, A.R. (1977) Hydroformylation of 1-hexene catalysed by complexes of rhodium(I) with di- or tritertiary phosphines. Journal of Molecular Catalysis, 3, 221; Sanger, A.R. and Schallig, L.R. (1977) The structures and hydroformylation catalytic activities of polyphosphine complexes of rhodium(I), and related complexes immobilised on polymer supports. Journal of Molecular Catalysis, 3, 101; Pittman, C.U. and Hirao, A. (1978) Hydroformylation catalyzed by cischelated rhodium complexes - extension to polymer-anchored cis-chelated rhodium catalysts. The Journal of Organic Chemistry, 43, 640.

20 van der Veen, L.A., Boele, M.D.K., Bregman, F.R., Kamer, P.C.J., van Leeuwen, P.W.N.M., Goubitz, K., Fraanje, J., Schenk, H. and Bo, C. (1998) Electronic effect on rhodium diphosphine catalyzed hydroformylation: the bite angle effect reconsidered. Journal of the American Chemical Society, 120, 11616.

21 van der Veen, L.A., Kamer, P.C.J. and van Leeuwen, P.W.N.M. (1999) New phosphacyclic diphosphines for rhodium catalyzed hydroformylation. Organometallics, 18, 4765.

22 Casey, C.P., Paulsen, E.L., Beuttenmueller, E.W., Proft, B.R., Petrovich, L.M., Matter, B.
A. and Powell, D.R. (1997) Electron withdrawing substituents on equatorial and apical phosphines have opposite effects on the regioselectivity of rhodium catalyzed hydroformylation. Journal of the American Chemical Society, 119, 11817; Casey, C.P., Paulsen, E.L., Beuttenmueller, E.W., Proft, B.R., Matter, B.A. and Powell, D.R. (1999) Electronically dissymmetric DIPHOS derivatives give higher $n: i$ regioselectivity in rhodium-catalyzed hydroformylation than either of their symmetric counterparts. Journal of the American Chemical Society, 121, 63; Herrmann, W.A., Kohlpaintner, C.W., Herdtweck, E. and Kiprof, P. (1991) Structure and metal coordination of the diphosphane 2,2'-bis((diphenylphosphino) methyl)-1,1'-biphenyl (BISBI). Inorganic Chemistry, 30, 4271.

23 Unruh, J.D. and Christenson, J.R. (1982) A study of the mechanism of rhodium phosphine catalyzed hydroformylation: use of 1,1'-bis(biarylphosphino) ferrocene ligands. Journal of Molecular Catalysis, 14, 19.

24 Zuidema, E., Escorihuela, L., Eichelsheim, T., Carbó, J.J., Bo, C., Kamer, P.C.J. and van Leeuwen, P.W.N.M. (2007) The ratedetermining step in the rhodium-xantphos catalyzed hydroformylation of 1-octene, Chem. Eur. J. B, accepted.

25 Kawabata, Y., Hayashi, T. and Ogata, I. (1979) Platinum-diphosphine-tin systems as active and selective hydroformylation catalysts. Journal of the Chemical Society, Chemical Communications, 462.

26 Hayashi, T., Kawabata, Y., Isoyama, T. and Ogata, I. (1981) Platinum chloridediphosphine-tin(II) halide systems as active and selective hydroformylation catalysts. Bulletin of the Chemical Society of Japan, 54, 3438; Schwager, I. and Knifton, J.F. (1976) Homogeneous olefin hydroformylation catalyzed by ligand stabilized platinum(II)group-IVb metal halide complexes. Journal of Catalysis, 45, 256; Ancillotti, F., Lami, M. and Marchionna, M. (1990)

Hydroformylation of Z-2-butene with the $\mathrm{PtCl}_{2}(\mathrm{cod}) / \mathrm{SnCl}_{2} / \mathrm{L}$ catalytic system. 
3. The effect of the phosphorus ligand L. Journal of Molecular Catalysis, 63, 15.

27 Tang, S.C. and Kim, L. (1982)

Homogeneous hydroformylation of internal olefins by platinum tin cationic complexes. Journal of Molecular Catalysis, 14 (1), 231; van Leeuwen, P.W.N.M., Roobeek, C.F., Wife, R.L. and Frijns, J.H.G. (1986) Platinum hydroformylation catalysts containing diphenylphosphine oxide ligands. Journal of the Chemical Society, Chemical Communications, (1), 31; Botteghi, C., Paganelli, S., Matteoli, U., Scrivanti, A., Ciorciaro, R. and Venanzi, L.M. (1990) A new catalytic system for the hydroformylation of styrene using alkene complexes of platinum(0). Helvetica Chimica Acta, 73, 284.

28 Meessen, P., Vogt, D. and Keim, W. (1998) High regioselective hydroformylation of internal, functionalized olefins applying PtSn complexes with large bite angle diphosphines. Journal of Organometallic Chemistry, 551, 165; van Duren, R., Cornelissen, L.L.J.M., Van der Vlugt, J.I., Huijbers, J.P.L., Mills, A.M., Spek, A.L., Muller, C. and Vogt, D. (2006) Chiral (diphosphonite)platinum complexes in asymmetric hydroformylation. Helvetica Chimica Acta, 89, 1547.

29 Agbossou, F., Carpentier, J.F. and Mortreux, A. (1995) Asymmetric hydroformylation. Chemical Reviews, 95, 2485.

30 van der Veen, L.A., Keeven, P.K., Kamer, P.C. J. and van Leeuwen, P.W.N.M. (2000) Wide bite angle amines, arsine and phosphine ligands in rhodium and platinum/tin catalysed hydroformylation. Journal of the Chemical Society, Dalton Transactions, 2105.

31 Sen, A. and Lai, T.W. (1982) Novel palladium(II) catalyzed copolymerization of carbon monoxide with olefins. Journal of the American Chemical Society, 104, 3520; Lai, T.W. and Sen, A. (1984) Palladium(II)catalyzed copolymerization of carbon monoxide with ethylene. Direct evidence for a single mode of chain growth. Organometallics, 3, 866.
32 Drent, E. (1984) Process for the preparation of polyketones. EP 0121965 (to Shell), Chemical Abstracts, 1985, 102, 464223.

33 Drent, E., Broekhoven, J.A.M. and Doyle, M.J. (1991) Efficient palladium catalyst for the copolymerization of carbon monoxide with olefins to produce perfectly alternating polyketones. Journal of Organometallic Chemistry, 417, 235.

34 del Rio, I., Claver, C. and van Leeuwen, P.W.N.M. (2001) On the mechanism of the hydroxycarbonylation of styrene with palladium systems. European Journal of Inorganic Chemistry, (11), 2719; Verspui, G., Moiseev, I.I. and Sheldon, R.A. (1999) Reaction intermediates in the Pd/tpptscatalyzed aqueous phase hydrocarboxylation of olefins monitored by NMR spectroscopy (tppts $=\mathrm{P}\left(\mathrm{C}_{6} \mathrm{H}_{4}-m\right.$ $\left.\left.\mathrm{SO}_{3} \mathrm{Na}\right)_{3}\right)$. Journal of Organometallic Chemistry, 586 (11), 196.

35 Doherty, S., Eastham, G.R., Tooze, R.P., Scanlan, T.H., Williams, D., Elsegood, M.R.J. and Clegg, W. (1999) Palladium complexes of C2-, C3- and C4-bridged bis(phospholyl) ligands: remarkably active catalysts for the copolymerization of ethylene and carbon monoxide. Organometallics, 18, 3558.

36 Zuideveld, M.A., Kamer, P.C.J., van Leeuwen, P.W.N.M., Klusener, P.A.A., Stil, H.A. and Roobeek, C.F. (1998) Chaintransfer mechanisms of the alternating copolymerization of carbon monoxide and ethene catalyzed by palladium(II) complexes: rearrangement to highly reactive enolates. Journal of the American Chemical Society, 120, 7977.

37 van Leeuwen, P.W.N.M., Zuideveld, M.A., Swennenhuis, B.H.G., Freixa, Z., Kamer, P.C.J., Goubitz, K., Fraanje, J., Lutz, M. and Spek, A.L. (2003) Alcoholysis of acylpalladium(II) complexes relevant to the alternating copolymerization of ethene and carbon monoxide and the alkoxycarbonylation of alkenes: the importance of cis-coordinating diphosphines. Journal of the American Chemical Society, 125, 5523. 
38 Mul, W.P., Dirkzwager, H., Broekhuis, A.A., Heeres, H.J., van der Linden, A.J. and Orpen, A.G. (2002) Highly active, recyclable catalyst for the manufacture of viscous, low molecular weight, CO-ethene-propene based polyketone, base component for a new class of resins. Inorganica Chimica Acta, 327, 147.

39 Bianchini, C., Lee, H.M., Meli, A., Moneti, S., Vizza, F., Fontani, M. and Zanello, P. (1999) Copolymerization of carbon monoxide with ethene catalyzed by palladium(II) complexes of 1,3-bis (diphenylphosphino)propane ligands bearing different substituents on the carbon backbone. Macromolecules, 32, 4183.

40 Bianchini, C., Lee, H.M., Meli, A., Oberhauser, W., Peruzzini, M. and Vizza, F. (2002) Ligand and solvent effects in the alternating copolymerization of carbon monoxide and olefins by palladiumdiphosphine catalysis. Organometallics, 21, 16.

41 Mul, W.P., Oosterbeek, H., Beitel, G.A., Kramer, G.-J. and Drent, E. (2000) in situ monitoring of a heterogeneous palladiumbased polyketone catalyst, Angewandte Chemie-International Edition, 39, 1848.

42 Dossett, S.J., Gillon, A., Orpen, A.G., Fleming, J.S., Pringle, P.G., Wass, D.F. and Jones, M.D. (2001) Steric activation of chelate catalysts: efficient polyketone catalysts based on four-membered palladium(II) diphosphine chelates. Journal of the Chemical Society, Chemical Communications, 699.

43 Drent, E. and Kragtwijk, E. (1992) Process for the carbonylation of olefin. EP 0495548 (to Shell).

44 Clegg, W., Eastham, G.R., Elsegood, M.R.J., Tooze, R.P., Wang, X.L. and Whiston, K. (1999) Highly active and selective catalysts for the production of methyl propanoate via the methoxycarbonylation of ethane. Journal of the Chemical Society, Chemical Communications, 1877; Tooze, R.P., Eastham, G.R., Whiston, K. and Wang, X.L. (1996) Process for the carbonylation of ethylene and catalyst system for use therein. WO 09619434 (to ICI PCL).
45 Pugh, R.I., Drent, E. and Pringle, P.G. (2001) Tandem isomerisationcarbonylation catalysis: highly active palladium(II) catalysts for the selective methoxycarbonylation of internal alkenes to linear esters. Journal of the Chemical Society, Chemical Communications, 1476.

46 Doherty, S., Robins, E.G., Knight, J.G., Newman, C.R., Rhodes, B., Champkin, P.A. and Clegg, W. (2001) Selectivity for the methoxycarbonylation of ethylene versus CO-ethylene copolymerization with catalysts based on C-4-bridged bidentate phosphines and phospholes. Journal of Organometallic Chemistry, 640, 182.

47 Drent, E., van Kragtwijk, E. and Pello, D.H. L. (1992) Carbonylation of olefins. EP 495547 (to Shell).

48 Gusev, O.V., Kalsin, A.M., Peterleitner, M. G., Petrovskii, P.V., Lyssenko, K.A., Akhmedov, N.G., Bianchini, C., Meli, A. and Oberhauser, W. (2002) Palladium(II) complexes with $1,1^{\prime}$-bis (diphenylphosphino) ferrocenes $\left[\mathrm{Fe}\left(\eta^{5}\right)\right.$ $\left.\left.\mathrm{C}_{5} \mathrm{R}_{4} \mathrm{PPh}_{2}\right)_{2}\right]^{n+}$ (dppf, $\mathrm{R}=\mathrm{H}, n=0$; dppomf, $\mathrm{R}=\mathrm{Me}, n=0$; dppomf $\left.{ }^{+}, \mathrm{R}=\mathrm{Me}, n=1\right)$. Synthesis, characterization, and catalytic activity in ethene methoxycarbonylation. Organometallics, 21, 3637.

49 Zuideveld, M.A., Swennenhuis, B.H.G., Boele, M.D.K., Guari, Y., van Strijdonck, G.P.F., Reek, J.N.H., Kamer, P.C.J., Goubitz, K., Fraanje, J., Lutz, M., Spek, A.L. and van Leeuwen, P.W.N.M. (2002) The coordination behaviour of large natural bite angle diphosphine ligands towards methyl and 4-cyanophenylpalladium(II) complexes. Journal of the Chemical Society, Dalton Transactions, 2308; Yin, J.J. and Buchwald, S.L. (2002) Pd-catalyzed intermolecular amidation of aryl halides: the discovery that xantphos can be transchelating in a palladium complex. Journal of the American Chemical Society, 124, 6043.

50 Pugh, R.I. and Drent, E. (2002) Methoxycarbonylation versus hydroacylation of ethene: dramatic influence of the ligand in cationic palladium catalysis. Advanced Synthesis \& Catalysis, 344, 837. 
51 Eastham, G.R., Heaton, B.T., Iggo, J.A., Tooze, R.P., Whyman, R. and Zacchini, S. (2000) Synthesis and spectroscopic characterisation of all the intermediates in the Pd-catalysed methoxycarbonylation of ethane. Journal of the Chemical Society, Chemical Communications, 609; Clegg, W., Eastham, G.R., Elsegood, M.R.J., Heaton, B.T., Iggo, J.A., Tooze, R.P., Whyman, R. and Zacchini, S. (2002) Characterization and dynamics of $[\mathrm{Pd}(\mathrm{L}-\mathrm{L}) \mathrm{H}$ (solv) $](+),\left[\mathrm{Pd}(\mathrm{L}-\mathrm{L})\left(\mathrm{CH}_{2} \mathrm{CH}_{3}\right)\right]^{+}$, and $[\mathrm{Pd}(\mathrm{L}-\mathrm{L})$ $(\mathrm{C}(\mathrm{O}) \mathrm{Et})(\mathrm{THF})]^{+}(\mathrm{L}-\mathrm{L}=1,2-$

$\left.\left(\mathrm{CH}_{2} \mathrm{PBu}_{2} t\right)_{2} \mathrm{C}_{6} \mathrm{H}_{4}\right)$ : key intermediates in the catalytic methoxycarbonylation of ethene to methylpropionate. Organometallics, 21, 1832; Liu, J.K., Heaton, B.T., Iggo, J.A., Whyman, R., Bickley, J.F. and Steiner, A. (2006) The mechanism of the hydroalkoxycarbonylation of ethene and alkene-CO copolymerization catalyzed by Pd-II-diphosphine cations. Chemistry - A European Journal, 12, 4417; Liu, J.K., Heaton, B.T., Iggo, J.A. and Whyman, R. (2004) The complete delineation of the initiation, propagation, and termination steps of the carbomethoxy cycle for the carboalkoxylation of ethene by Pddiphosphane catalysts. Angewandte ChemieInternational Edition in English, 43, 90.

52 Tooze, R.P., Whiston, K., Malyan, A.P., Taylor, M.J. and Wilson, N.W. (2000) Evidence for the hydride mechanism in the methoxycarbonylation of ethene catalysed by palladium-triphenylphosphine complexes. Journal of the Chemical Society, Dalton Transactions, 3441.

53 Zuidema, E., Bo, C. and van Leeuwen, P.W. N.M. (2007) Ester versus polyketone formation in the palladium-diphosphine catalyzed carbonylation of ethene. Journal of the American Chemical Society, 129, 3989.

54 Smejkal, Q., Linke, D. and Baerns, M. (2005) Energetic and economic evaluation of the production of acetic acid via ethane oxidation. Chemical Engineering and Processing, 44, 421.

55 http://www.greener-industry.org/(2007).

56 Gaemers, S. and Sunley, G.J. (2004) Carbonylation process using metal-polydentate ligands catalysis. WO 2004101487 (to BP Chemicals Limited).

57 Gaemers, S. and Sunley, G.J. (2004) Carbonylation process using metaltridentate ligand catalysts. WO 2004101488 (to BP Chemicals Limited).

58 Moloy, K.G. and Wegman, R.W. (1989) Rhodium-catalyzed reductive carbonylation of methanol. Organometallics, 8, 2883; Moloy, K.G. and Petersen, R.A. (1995) Structural characterization of intermediates in the rhodium-catalyzed reductive carbonylation of methanol: $\mathrm{Rh}\left(\mathrm{COCH}_{3}\right)\left(\mathrm{I}_{2}\right)$ (dppp) and $[\mathrm{Rh}(\mathrm{H})(\mu-\mathrm{I})(\mathrm{dppp})]_{2}$. Organometallics, 14, 2931.

59 Freixa, Z., Kamer, P.C.J., Lutz, M., Spek, A. L. and van Leeuwen, P.W.N.M. (2005) Activity of SPANphos rhodium dimers in methanol carbonylation. Angewandte Chemie-International Edition, 44, 4385.

60 Müller, C., Freixa, Z., Spek, A.L., Lutz, M., Vogt, D. and van Leeuwen, P.W.N.M. (2007) Wide bite angle diphosphines: design, synthesis and coordination properties. Organometallics, submitted.

61 Broussier, R., Laly, M., Perron, P., Gautheron, B., Nifant'ev, I.E., Howard, J.A.K., Kuz'mina, L.G. and Kalck, P. (1999) Neutral and cationic 1,4-diphospha-2-rhoda-3-thia-4ferrocenophane. Journal of Organometallic Chemistry, 587, 104; Martin, H.C., James, N. H., Aitken, J., Gaunt, J.A., Adams, H. and Haynes, A. (2003) Oxidative addition of MeI to a rhodium(I) $\mathrm{N}$-heterocyclic carbene complex. A kinetic study. Organometallics, 22, 4451.

62 Griffin, T.R., Cook, D.B., Haynes, A., Pearson, J.M., Monti, D. and Morris, G.E. (1996) Theoretical and experimental evidence for $\mathrm{S}_{\mathrm{N}} 2$ transition states in oxidative addition of methyl iodide to cis- $\left[\mathrm{M}(\mathrm{CO})_{2} \mathrm{I}_{2}\right]^{-}$ $(\mathrm{M}=\mathrm{Rh}, \mathrm{Ir})$. Journal of the American Chemical Society, 118, 3029; Chauby, V., Daran, J.-C., Berre, C.S.-L., Malbosc, F., Kalck, P., Gonzalez, O.D., Haslam, C.E. and Haynes, A. (2002) A mechanistic investigation of oxidative addition of methyl iodide to [TpRh(CO)L]. Inorganic Chemistry, 41, 3280 . 
63 Forster, D. (1976) Mechanism of a rhodiumcomplex-catalyzed carbonylation of methanol to acetic acid. Journal of the American Chemical Society, 98, 846; Adamson, G.W., Daly, J.J. and Forster, D. (1974) Reaction of iodocarbonylrhodium ions with methyliodide - structure of rhodium acetyl complex $-\left[\mathrm{Me}_{3} \mathrm{PhN}^{+}\right]_{2}\left[\mathrm{Rh}_{2} \mathrm{I}_{6}(\mathrm{MeCO})_{2}(\mathrm{CO})_{2}\right]^{2-}$. Journal of Organometallic Chemistry, 71, C17; Haynes, A., Mann, B.E., Gulliver, D.J., Morris, D.E. and Maitlis, P.M. (1991) Direct observation of $\mathrm{MeRh}(\mathrm{CO})_{2} \mathrm{I}_{3}{ }^{-}$: the key intermediate in rhodium catalyzed methanol carbonylation. Journal of the American Chemical Society, 113, 8567; Haynes, A., Mann, B.E., Morris, G.E. and Maitlis, P.M. (1993) Mechanistic studies on rhodiumcatalyzed carbonylation reactions spectroscopic detection and reactivity of a key intermediate, $\left[\mathrm{MeRh}(\mathrm{CO})_{2} \mathrm{I}_{3}\right]^{-}$. Journal of the American Chemical Society, 115, 4093.

64 Cheong, M. and Ziegler, T. (2005) Density functional study of the oxidative addition step in the carbonylation of methanol catalyzed by $\left[\mathrm{M}(\mathrm{CO})_{2} \mathrm{I}_{2}\right]^{-}(\mathrm{M}=\mathrm{Rh}, \mathrm{Ir})$. Organometallics, 24, 3053; Feliz, M., Freixa, Z., van Leeuwen, P.W.N.M. and Bo, C. (2005) Revisiting the methyl iodide oxidative addition to rhodium complexes: a DFT study of the activation parameters. Organometallics, 24, 5718; Kinnunen, T. and Laasonen, K. (2001) The oxidative addition and migratory 1,1- insertion in the Monsanto and Cativa processes. A density functional study of the catalytic carbonylation of methanol. Journal of Molecular Structure: Theochem, 542, 273.

65 Thomas, C.M., Mafua, R., Therrien, B., Rusanov, E., Stoeckli-Evans, H. and SüssFink, G. (2002) New diphosphine ligands containing ethyleneglycol and amino alcohol spacers for the rhodium-catalyzed carbonylation of methanol. Chemistry - A European Journal, 8, 3343; Thomas, C.M. and Süss-Fink, G. (2003) Ligand effects in the rhodium-catalyzed carbonylation of methanol. Coordination Chemistry Reviews, 243, 125; Burger, S., Therrien, B. and SüssFink, G. (2005) Square-planar carbonylchlororhodium(I) complexes containing trans-spanning diphosphine ligands as catalysts for the carbonylation of methanol. Helvetica Chimica Acta, 88, 478.

66 Wells, J., Williams, G.L., Haynes, A., Freixa, Z. and van Leeuwen, P.W.N.M., unpublished results.

67 Kranenburg, M., Kamer, P.C.J., van Leeuwen, P.W.N.M., Vogt, D. and Keim, W. (1995) Effect of the bite angle of diphosphines ligands on activity and selectivity in the nickel-catalysed hydrocyanation of styrene. Journal of the Chemical Society, Chemical Communications, 2177. 
